\title{
The Hospitalist Perspective on Opioid Prescribing: A Qualitative Analysis
}

\author{
Susan L. Calcaterra, MD, MPH${ }^{1,2 *}$, Anne D. Drabkin, MD¹,2, Sarah E. Leslie, MPH ${ }^{3}$, Reina Doyle, MPH ${ }^{3}$, Stephen Koester, PhD ${ }^{4,5}$, \\ Joseph W. Frank, MD, MPH²,6, Jennifer A. Reich, $\mathrm{PhD}^{7}$, Ingrid A. Binswanger, MD, MPH'1,2,8
}

\begin{abstract}
${ }^{1}$ Department of Hospital Medicine, Denver Health Medical Center, Denver, Colorado; ${ }^{2}$ Division of General Internal Medicine, Department of Medicine, University of Colorado School of Medicine, Aurora, Colorado; ${ }^{3}$ Center for Health Systems Research, Denver Health Medical Center, Denver, Colorado; ${ }^{4}$ Department of Anthropology, University of Colorado, Denver, Colorado; ${ }^{5}$ Department of Health and Behavioral Sciences, University of Colorado Denver, Denver, Colorado; ${ }^{6}$ VA Eastern Colorado Health Care System, Denver, Colorado; 'Department of Sociology, University of Colorado, Denver, Colorado; ${ }^{I}$ nstitute for Health Research, Kaiser Permanente Colorado, Denver, Colorado.
\end{abstract}

BACKGROUND: Pain is a frequent symptom among patients in the hospital. Pain management is a key quality indicator for hospitals, and hospitalists are encouraged to frequently assess and treat pain. Optimal opioid prescribing, described as safe, patient-centered, and informed opioid prescribing, may be at odds with the priorities of current hospital care, which focuses on patient-reported pain control rather than the potential long-term consequences of opioid use.

OBJECTIVE: We aimed to understand physicians' attitudes, beliefs, and practices toward opioid prescribing during hospitalization and discharge.

DESIGN: In-depth, semistructured interviews.

SETTING: Two university hospitals, a safety-net hospital, a Veterans Affairs hospital, and a private hospital located in Denver, Colorado or Charleston, South Carolina.

PARTICIPANTS: Hospitalists ( $N=25)$.
MEASUREMENTS: We systematically analyzed transcribed interviews and identified emerging themes using a teambased mixed inductive and deductive approach.

RESULTS: Although hospitalists felt confident in their ability to control acute pain using opioid medications, they perceived limited success and satisfaction when managing acute exacerbations of chronic pain with opioids. Hospitalists recounted negative sentinel events that altered opioid prescribing practices in both the hospital setting and at the time of hospital discharge. Hospitalists described prescribing opioids as a pragmatic tool to facilitate hospital discharges or prevent readmissions. At times, this left them feeling conflicted about how this practice could impact the patient over the long term.

CONCLUSIONS: Strategies to provide adequate pain relief to hospitalized patients, which allow hospitalists to safely and optimally prescribe opioids while maintaining current standards of efficiency, are urgently needed. Journal of Hospital Medicine 2016;11:536-542. (C) 2016 Society of Hospital Medicine
Pain is a frequent symptom among patients seen in the hospital. ${ }^{1-3}$ Hospitalized patients often suffer before they come to the hospital and are commonly prescribed opioids in the months preceding their hospital stay. ${ }^{4}$ Adequate pain control is important because uncontrolled pain is associated with higher levels of depression and anxiety among hospitalized patients. ${ }^{5}$ In 2011, the Institute of Medicine called on healthcare providers to improve pain assessment and management in healthcare delivery. ${ }^{6}$ Since then, pain management has become a key quality indicator for hospitals, and providers are encouraged to frequently assess and treat pain. ${ }^{7-10}$ Although the use of opioids for pain management among hospitalized patients is routine, the amount of opioids prescribed per patient varies widely between institutions. ${ }^{11}$ In-hospital guidelines for the optimal management of acute exacerbations of chronic pain are lacking.

\footnotetext{
*Address for correspondence and reprint requests: Susan Calcaterra MD, 1216 Race Street, Denver, CO 8020; Telephone: 248-703-5947; Fax: 303-602-5056; E-mail: susan.calcaterra@ucdenver.edu

Additional Supporting Information may be found in the online version of this article.

Received: November 5, 2015; Revised: March 7, 2016; Accepted: March 15, 2016

2016 Society of Hospital Medicine DOI 10.1002/jhm.2602

Published online in Wiley Online Library (Wileyonlinelibrary.com).
}

Pain management also carries risks. Recently, the Centers for Disease Control and Prevention urged clinicians to prevent opioid overdoses by following best prescribing practices including screening patients for substance use disorders, mental health issues, and avoiding combinations of opioids and sedatives. ${ }^{12,13}$ These guidelines may be at odds with the priorities of current hospital care, which focus on patient-perceived pain control rather than potential long-term consequences of opioid use. ${ }^{7,8,14}$ In light of the competing demands to provide adequate pain relief to hospitalized patients while optimally prescribing opioids, we sought to understand physicians' attitudes, beliefs, and experiences that inform opioid prescribing practices during hospitalization and at discharge.

\section{METHODS}

\section{Study Design, Setting, and Participants}

Between January 2015 and August 2015, we recruited a convenience sample via e-mail solicitation from approximately 135 hospitalists practicing in Colorado and South Carolina. ${ }^{15}$ Fifty-three physicians responded. We conducted 25 in-depth, semistructured interviews with physicians who represented the average hospitalist practicing in the United States in terms of years in practice and gender. ${ }^{16}$ We enrolled physicians working in 4 distinct types 
TABLE 1. A Complete List of Identified Emergent Themes With Hospitalist Physicians Regarding Opioid Prescribing Practices*

Perceived success, satisfaction, comfort, and the use of opioids for pain management Professional experiences influenced opioid prescribing practices*

The use of opioids to improve efficiency*

Skepticism between other physician subspecialty types and opioid prescribing practices Unintended consequences of patient-perceived pain control metrics and opioid prescribing Lack of trust with patients when reported pain level was not supported with objective data Resident burnout contributed to a lack of empathy and undertreatment of pain

Limited perceived risk of personal opioid prescribing practices and patient overdose with short-acting opioids

Unreal expectations by patients to have complete pain eradication contributes to overprescribing Recognition that patient profiling impacts personal opioid-prescribing practices

NOTE: *Discussed in the article.

of hospital settings, including 2 university hospitals, a safety-net hospital, a Veterans Affairs hospital, and a private hospital. We used purposive sampling to achieve an even distribution with respect to gender and years in practice. ${ }^{17}$ Interviews were either face-to-face $(n=16)$ or over the telephone $(n=9)$ and were performed outside of the physician's clinical shift. Informed consent was obtained from study participants, and the interview duration was approximately 1 hour. The study was approved by the Colorado Multiple Institutional Review Board.

\section{Interview Guide Development and Content}

Members of our multidisciplinary team (S.L.C., I.A.B., S.K.) developed an interview guide designed to explore hospitalists' attitudes and practices about opioid prescribing during hospitalization and at discharge (see Supporting Information, Appendix 1, in the online version of this article). Initial interview questions were developed with input from health sciences researchers (S.E.L., A.D.D., R.D.) and qualitative researchers (I.A.B., S.K.). During data collection, we occasionally edited or added questions to our guide to more fully explore new issues or information emerging from our interviews. Through open-ended interviews, we sought to capture a qualitative narrative in which hospitalists would describe their attitudes and practices that may influence opioid prescribing within 3 major domains pertinent to clinical practice: patient factors, ${ }^{18-23}$ physician factors, ${ }^{24-27}$ and institutional factors. ${ }^{27-32}$ These domains were based on prior literature. All participants received a $\$ 25$ gift card.

\section{Data Analysis}

Interview transcripts and a demographic survey were our primary data sources. Transcript files were entered into qualitative data analysis software (ATLAS.ti; Scientific Software Development GmbH, Berlin, Germany). We used a mixed inductive and deductive, ${ }^{33}$ participatory, team-based approach to explore patterns and themes related to attitudes and practices around opioid prescribing. ${ }^{34,35}$ A deductive or "top-down" approach was used to link text to predefined codes and categories based on literature, prior knowledge, and our interview guide. An inductive or "bottom-up" approach was used to identify new codes and categories that emerged from the data, including unanticipated information relevant to our research questions.

Team members included 2 hospitalists (S.L.C., A.D.D.), 2 research assistants with experience in qualitative methods (S.E.L., R.D.), an addiction medicine physician and researcher (I.A.B.), and a medical anthropologist (S.K.). S.L.C. performed initial coding using an a priori template that reflected the primary areas of interest in the study. The codes were categorized as patient, physician, and institutional factors. Using this template as a guide, 3 other team members (S.E.L., A.D.D., R.D.) independently coded 3 transcripts by assigning predefined codes to text and assigning new codes to emergent findings. Using this subset of 4 transcripts, the team reached a consensus on initial codes to be applied to the remaining transcripts. In weekly meetings, team members discussed and modified the codebook based on inconsistencies noted among team members to refine the coding scheme and to ensure consensus. Through group consensus, codes were condensed into a list of categories, subcategories, and emergent themes (ie, themes that did not originate from summarized answers to specific interview questions). The team identified emergent themes represented across all major domains (Table 1). Three of the most prevalent themes representing physicians' personal opioid prescribing practices are reported here. The study team determined that thematic saturation was reached after 25 interviews, as additional interview data created little change to the codebook and no new patterns or themes emerged.

\section{RESULTS}

Of the 25 hospitalist participants who were all trained in internal medicine, $16(64 \%)$ were women. The majority were non-Hispanic white $(21[84 \%])$. Nine physicians $(36 \%)$ completed residency within the past 5 years, $12(48 \%)$ completed residency within the past 5 to 10 years, and $4(16 \%)$ completed residency $>10$ years ago. Sixteen $(64 \%)$ hospitalists practiced medicine in Colorado, where $8(32 \%)$ worked in a safety-net hospital, $5(20 \%)$ worked in a university hospital, and $3(12 \%)$ worked in a Veterans Affairs hospital. Nine hospitalists $(36 \%)$ practiced in South Carolina, where $2(8 \%)$ worked in a university hospital and $7(28 \%)$ worked in a private hospital (Table 2).

Emergent themes described here include: (1) hospitalists' perceived success, satisfaction, and comfort when prescribing opioids for their patients' pain management; (2) the influence of physicians' professional sentinel experiences on opioid prescribing practices; and (3) opioid prescribing as a tool to improve efficiency in the hospital. Additional quotations to support emergent themes are listed in Table 3. 


\section{Perceived Success, Satisfaction, and Comfort When Prescribing Opioids for Pain Management}

Providing adequate pain control to their patients was of utmost importance to hospitalists and influenced

\begin{tabular}{lr}
\hline \multicolumn{2}{l}{ TABLE 2. Participant Characteristics $(\mathrm{N}=25)$} \\
\hline Female, no. (\%) & $16(64)$ \\
Race/ethnicity, no. (\%) & $21(84)$ \\
White, non-Hispanic & $4(16)$ \\
Asian, non-Hispanic & \\
Years postresidency, no. (\%) & $9(36)$ \\
$<5$ & $12(48)$ \\
$5-10$ & $4(16)$ \\
$>10$ & $16(64)$ \\
State of practice, no. (\%) & $9(36)$ \\
Colorado & $7(28)$ \\
South Carolina & \\
Private hospital, no. (\%) & $8(32)$ \\
Academic institution, no. (\%) & $3(12)$ \\
Safety-net hospital & $7(28)$ \\
Veteran Affairs hospital & \\
University hospital &
\end{tabular}

opioid prescribing. Hospitalists felt confident in their ability to control acute pain using opioids, but notably perceived limited success in achieving adequate patient-perceived pain control when treating acute exacerbations of chronic pain with opioids. A physician described his confidence in treating severe, acute pain:

"If someone is dying of cancer, or if they have an acutely broken femur, I don't really care if they are actively in the 12-Step Program or Narcotics Anonymous to stay sober. That pain is real and there is no effective pain medicine on earth except for opioids.”

Managing exacerbations of chronic pain with increasing opioid doses left physicians feeling frustrated and uncomfortable, especially when they lacked objective findings to explain the reported pain. Physicians were concerned that, by increasing opioid doses, they may be contributing to opioid dependence or addiction. A physician explained his dilemma when treating chronic pain:

TABLE 3. Selected Emergent Themes With Illustrative Quotations

Theme Illustrative Quote

Perceived success, satisfaction, comfort, and the use of opioids for pain management

Professional experiences that influenced opioid prescribing practices

The use of opioids to improve efficiency
Acute pain: "I'm more comfortable treating acute pain. With chronic pain, it depends on the circumstance. There are certain people who have objective reasons to have chronic pain, for instance they have severe degenerate disc disease, for example. With chronic pain. . .let me just say, getting their pain under control is quite challenging. Acute pain is much more straight forward to treat."

Chronic pain; "If I am treating an exacerbation of someone's chronic pain, it makes me a little less comfortable as far as sending people out on large doses of opioids because of the whole addiction thought behind it. And you don't want to start or feed people's addiction. Or, you know, lead them to it, in the future, requiring increased doses of opioids."

Chronic pain: "I have a hard time feeling like I'm very successful with people who have chronic noncancer pain who come in for an exacerbation. Unless I can figure out clear reasons for that exacerbation, I feel I rarely succeed in having the patient, the providers, and the caregivers be happy. It is an unrewarding situation all around."

Chronic pain: "I'm less comfortable treating chronic pain because we don't know the patients as well, I think, in the hospital, and you just worry about people abusing the system to get their needs met while they are in the hospital. We don't have much objective data in terms of assessing pain, and you know, they are on chronic narcotics, you don't really know what to believe, I guess."

In the hospital: "I had 1 horrible experience. I had a young woman who came in with chronic abdominal pain. She told me how much opioids she took. It was before there was a statewide database and I couldn't verify her doses. I gave her what she told me she was taking. I hadn't put a pulse ox on her which I always do now because it makes me feel better. Later the nurse called and said she wasn't responsive. I put her on Pulse $0 x$ and she was sating $30 \%$ and blue. A code was called and we brought her back. That was in my mind for ever, I almost killed a 23 year old."

In the hospital: "I think past experiences inform what I do now. I mean it's not that I've murdered anybody, but there was a time when I took over a patient and didn't realize that, while she had terrible pain from her restless leg syndrome, she also had severe pulmonary hypertension. I gave her $5 \mathrm{mg}$ of oxycodone. She ended up somnolent with hypercarbic respiratory failure. I think that is something that will always stick in my head."

Discharge: "When discussing what type of opioids prescribed at discharge. . I worry about, not just deliberate diversion, but for the patient being robbed, for the type of opioid I might choose. So I might do oxycodone instead of Percocet. Percocet, itself, has a higher street value then oxycodone. That may be completely false, but I think of it as a name brand that people want."

Discharge: "I think many providers, including myself, try to minimize the use of opiates when we can. I think we are all concerned every time we write, you know, our DEA \#. Even when we have other providers ask us, you know, to prescribe opioids for their patients because they are out of the hospital or something like that, it is always a touchy subject. Because I think we all feel like our license is always at risk every time we are writing opioids."

Discharge: "I give them what they need but I want them to be seen in follow-up. I encourage that by giving them a shortened course. I'm more skeptical. I've seen people misuse, have bad side effects, and overdose on opioids. I worry about that, so I tend to prescribe shorter courses and less."

"There is always the group of patients [for whom] we've done everything we can. We set up follow-up. If giving you a few days of Percocet is going to help you leave the hospital comfortably and stay out of the hospital for appropriate reasons, then we give them a few days. It's horrible but..."

I'll give 4 or 6 weeks' worth of opioid medication to the chronic abdominal pain patients, the ones who have ERCPs scheduled for every 4 or 6 weeks. You sort of end up managing their chronic pain. It's the people that we know. If you don't give them a month's worth of pain meds, they are going to come back in to the hospital. Because they always come in when they run out.

"I think physicians overprescribe opioids because we don't want people to bounce back to the hospital. We don't want them to have acute pain at home and have to go back to the ER to be readmitted. You don't want someone to be in pain. I think that sometimes people go overboard. I also think that sometimes physicians gauge like, oh, this person isn't a huge risk, and maybe give them more opioids than necessary." 
"[I am uncomfortable treating] people that you classify with chronic pain syndrome. There is that terminology you use for people who have subjective pain, out of proportion to objective findings. In my experience it is a black hole. You never get an adequate level of pain control and you keep adding the doses up and they get habituated. An end point is very difficult to achieve. Not like with acute pain.”

Hospitalists described awareness that patients' reports of pain management were part of the evaluation of their care, and expressed concern that these patient-perceived pain control metrics for quality care were inappropriately applied to patients with chronic pain, and may even be unsafe. A physician explained his experience with chronic pain management among hospitalized patients:

"All of these things you do for patient satisfaction set up people, who aren't ever going to be without pain, to fail. They have pain all the time, and now you are asking them about their pain. Well, of course their pain is not controlled, because their pain is never going to be less than 5 out of 10, period. And no opioid is going to get them there, unless they are unconscious."

\section{Professional Experiences Influenced Opioid Prescribing Practices}

Physicians reported little opioid-specific training during residency, and so opioid prescribing practices were shaped by the physicians' clinical experiences. Hospitalists reflected on negative, sentinel events that shaped their opioid prescribing practices in the inpatient setting or led them to adopt risk-modifying behaviors when prescribing opioids at hospital discharge. Negative experiences varied and included a fatal overdose and suspected diversion of opioids for sale. A physician reflected on an avoidable in-hospital overdose which left her more guarded when prescribing opioids:

"It is both your cumulative experience and, sometimes, when you've had a negative experience, it really biases how you think. I've had an experience where my patient actually overdosed. She crushed up the oxycodone we were giving her in the hospital and shot it up through her central line and died. We've all had experiences with opioids being abused. This just happened to be a very dramatic thing that happened right under my nose. It just makes me more guarded, in terms of my practice, and the lengths people will go through to do harm to themselves with opioids."

Hospitalists recognized that some of their patients had limited resources. They expressed suspicions that opioid prescriptions, in some cases, represented a form of currency for patients to supplement their income. A physician stated:

"I think our population can divert quite a few meds. I think their financial situations can be really tenuous. Sometimes they sell pills to survive."

Physicians described past experiences with patients who were deceptive to get an opioid prescription, which left them much more reticent to prescribe the drugs. For example, a physician described how a patient altered her opioid prescription following hospital discharge:

"I saw a patient who had her gallbladder removed. She asked for an opioid script until she could see her primary care physician, so I gave her a few days of opioids. I later found out she had forged my script and had changed it from 18 pills to 180 pills. She took it all over the state to try to fill. I got a call from the DEA [Drug Enforcement Administration] and had to write them a letter. I think she's in prison now."

These experiences inspired hospitalists to adopt strategies around opioid prescribing that would make it harder for a patient to misuse a prescription or to jeopardize their DEA license. A physician discussed her technique to prevent patients from selling their opioid prescriptions following discharge:

"When I write the prescription, I put the name of the patient on the paper prescription with the patient's sticker on top. I don't want the patients to pull it off and sell the prescription, especially when it is my license."

Another physician described feeling reassured when she is able to verify a patient's opioid dose in a statewide prescription monitoring program:

"Seeing they have filled opioids before supports your decision making. You just sort of cross your finger that this time my DEA number is not going to come up on the next drug bust!"

\section{The Use of Opioids to Improve Institutional Efficiency}

Hospitalists felt institutional pressure to reduce hospital readmissions and to facilitate discharges. Pain was a common complaint among patients admitted to the hospital, and uncontrolled pain often prolonged a hospital stay. In these ways, physicians viewed opioid prescriptions as a tool to buffer against readmission or long hospital stays. A physician described his approach to more readily prescribed opioids when he 
felt it would prevent a patient from being rehospitalized:

"If a patient tells you that they are in pain and they are receiving opioids in the hospital, and I have a strong sense that this is a person who comes back to the hospital easily and regularly if something is not right, I'm more likely to make sure that patient has adequate pain medicine for a reasonable duration of time to reduce the chance that they get readmitted just for pain alone."

Physicians used opioids as a tool to facilitate discharges and prevent readmissions; yet doing so sometimes left them feeling conflicted. On one hand, they felt pressured to maintain efficiency; on the other hand, they recognized it might not be in the patient's best interest to receive a higher than necessary quantity of opioids at discharge. A physician described his dilemma:

"For the acute pain, I usually give them 15 to 20 [opioid pills]. For the chronics, maybe a little bit more like 30. A lot of them have told me they can just buy it off the street anyway. If we can help keep them out of the hospital, we are probably doing them a disservice [by prescribing more opioids], but we are also not clogging up our system."

Similarly, another hospitalist described opioid prescribing at discharge as a way to reduce hospital costs and prevent a readmission, despite feeling uncomfortable when a patient's diagnosis of pain was nebulous:

"If the patient comes back and gets readmitted to the hospital when they don't have pain medicine, it's a $\$ 3,000.00,2$-day stay in the hospital that was unnecessary. And when they have a prescription for a month of pain medicine, they stay out of the hospital. That is utterly pragmatic...there is no other way to do it and it's going to work. At other times, especially when a patient lacks a diagnosis which is known to cause pain, it can feel cheap and dirty."

\section{DISCUSSION}

To our knowledge, this is the first study to qualitatively explore the hospitalist perspective on opioid prescribing during hospitalization and at discharge. Hospitalists expressed discomfort and dissatisfaction when managing acute exacerbations of chronic pain with opioid medications. This stemmed from the discordance between the patients' expressed pain and the lack of objective clinical findings of pain, a perceived inability to adequately provide relief to patients with chronic pain, and a concern of contributing to future opioid dependence. Hospitalists identified negative professional experiences with opioid prescribing as a factor that influenced their opioid prescribing practices. Hospitalists also described using opioids as a tool to reduce readmissions and facilitate hospital discharges to contain healthcare costs. This sometimes left them feeling conflicted, especially when their patients lacked clear, pain-related diagnoses.

Hospitalists were reluctant to increase patients' chronic opioid therapy doses, even when patients had acute exacerbations of chronic pain. Management of chronic pain presents a unique challenge to hospitalists. Existing clinical guidelines for chronic pain management are directed to the primary care physician. ${ }^{36,37}$ Acute exacerbations of chronic pain are commonly seen in hospitalized patients and should not be overlooked. ${ }^{4}$ Management strategies that include in-hospital, guideline-based opioid dose adjustments are needed to address some of the concern hospitalists feel when managing chronic pain exacerbations. Involving the patient in the decision to temporarily increase their opioid dose may improve patient-perceived pain control. ${ }^{38}$ In addition, when possible, close communication between the hospitalist and the primary care physician may alleviate some of the uncertainty hospitalists feel when they prescribe an increased dose of chronic opioid therapy. 39,40

Opioid prescribing practices by hospitalists were influenced by past negative experiences. This principle, defined as negativity bias, refers to the notion that in most situations, negative events are more salient, potent, and dominant than positive events. ${ }^{41,42}$ Hospitalists recounted situations in which their patients overdosed on opioids in the hospital or forged an opioid prescription, which they perceived as jeopardizing their DEA licenses or reputations. They described concrete practice changes they made in an attempt to avoid these situations in the future. Whereas it is appropriate to critically assess practice behaviors that contribute to unanticipated patient outcomes, there may be unintended consequences when providers narrowly focus on the negative, including the undertreatment of pain. Focusing on successful outcomes associated with opioid prescribing, rather than negative outcomes, may lead to less restrictive and more thoughtful opioid prescribing practices. Furthermore, standardizing opioid prescribing to protect physicians from medicolegal consequences related to opioid diversion and fraud could lessen physicians' fears when prescribing opioids both during the hospitalization and at hospital discharge.

Hospitalists described prescribing opioids as a tool to improve efficiency in their practice, although at times it left them feeling conflicted. We interpreted this as a form of cognitive dissonance. ${ }^{43}$ Hospitalists are acutely aware of the need to prevent costly hospital readmissions for their own success and longevity, which may lead them to become less judicious about how they prescribe opioids. ${ }^{4-46}$ Our findings suggest a delicate balance between the potential benefits and drawbacks of using opioids to improve efficiency. Whereas it is important to provide pain relief to the 
patient, which can facilitate a discharge or delay time to next hospital admission, using opioids to smooth a difficult discharge may be detrimental to the patient. These findings highlight the competing pressures hospitalists face to deliver value-based care ${ }^{46,47}$ while maintaining patient-centered care. ${ }^{48,49}$

This study has several limitations. First, qualitative data provide depth to the understanding of a behavior, but not breadth. ${ }^{50,51}$ Therefore, these results may not be generalizable to all hospitalists. We included a convenience sample of hospitalists who practiced in diverse settings including academic and private hospitals and the western and southern regions of the United States. The majority of the hospitalists interviewed had clinical experience less than 10 years. A national survey of hospitalists found the mean years of experience to be 6.9 years $^{16}$; thus, the hospitalists we interviewed are likely representative of hospitalists nationally when considering clinical experience. Second, our interview guide was informed by prior literature and an a priori knowledge based on our experience as practicing hospitalist physicians. Interviews were conducted by 2 hospitalists who may have had similar experiences as those being described by the interviewees. Having shared experiences facilitated rapport and understating between the interviewers and participants; at the same time, however, shared experiences may have narrowed the focus of the interviews, eliminating themes that were already assumed. Lastly, hospitalists who chose to be interviewed may have participated because they felt strongly about the issues discussed and may not fully represent the population from which the sample was drawn. ${ }^{15}$

The development of evidence-based strategies to promote optimal opioid prescribing for the management of acute exacerbations of chronic pain among hospitalized patients may benefit both hospital providers and patients who have a mutual goal for safe and effective pain relief. Methods to provide adequate pain relief to patients that allow hospitalists to maintain efficiency, while ensuring protection from medicolegal consequences related to opioid diversion or opioid overdose, are urgently needed.

Disclosures: This work was supported by the Denver Health Department of Medicine Small Grants Program, which was not involved in the design, conduct, or reporting of the study, or in the decision to submit the manuscript for publication. Dr. Binswanger was supported by the National Institute On Drug Abuse of the National Institutes of Health under award number R34DA035952. The content is solely the responsibility of the authors and does not necessarily represent the official views of the National Institutes of Health. The authors declare that they do not have any conflicts of interest.

\section{References}

1. Abbott FV, Gray-Donald K, Sewitch MJ, Johnston CC, Edgar L, Jeans ME. The prevalence of pain in hospitalized patients and resolution over six months. Pain. 1992;50(1):15-28.

2. Marks RM, Sachar EJ. Undertreatment of medical inpatients with narcotic analgesics. Ann Intern Med. 1973;78(2):173-181.

3. Desbiens NA, Wu AW. Pain and suffering in seriously ill hospitalized patients. J Am Geriatr Soc. 2000;48(5 suppl):S183-S186.
4. Mosher HJ, Jiang L, Vaughan Sarrazin MS, Cram P, Kaboli PJ, Vander Weg MW. Prevalence and characteristics of hospitalized adults on chronic opioid therapy. J Hosp Med. 2014;9(2):82-87.

5. Rockett MP, Simpson G, Crossley R, Blowey S. Characteristics of pain in hospitalized medical patients, surgical patients, and outpatients attending a pain management centre. Br J Anaesth. 2013; 110(6):1017-1023.

6. Institute of Medicine (US) Committee on Advancing Pain Research, Care, and Education. Relieving Pain in America: A Blueprint for Transforming Prevention, Care, Education, and Research. Washington, DC: National Academy of Sciences; 2011.

7. Gupta A, Daigle S, Mojica J, Hurley RW. Patient perception of pain care in hospitals in the United States. J Pain Res. 2009;2:157-164.

8. Lanser P, Gesell S. Pain management: the fifth vital sign. Healthc Benchmarks. 2001;8(6):68-70, 62.

9. Phillips S, Gift M, Gelot S, Duong M, Tapp H. Assessing the relationship between the level of pain control and patient satisfaction. J Pain Res. 2013;6:683-689.

10. Zgierska A, Rabago D, Miller MM. Impact of patient satisfaction ratings on physicians and clinical care. Patient Prefer Adherence. 2014;8: 437-446.

11. Herzig SJ, Rothberg MB, Cheung M, Ngo LH, Marcantonio ER. Opioid utilization and opioid-related adverse events in non-surgical patients in U.S. hospitals. J Hosp Med. 2014;9(2):73-81.

12. Centers for Disease Control and Prevention. CDC grand rounds: prescription drug overdoses-a U.S. epidemic. MMWR Morb Mortal Wkly Rep. 2012;61(1):10-13.

13. Centers for Disease Control and Prevention. Vital signs: overdoses of prescription opioid pain relievers and other drugs among womenUnited States, 1999-2010. MMWR Morb Mortal Wkly Rep. 2013; 62(26):537-542.

14. Gupta A, Lee LK, Mojica JJ, Nairizi A, George SJ. Patient perception of pain care in the United States: a 5-year comparative analysis of hospital consumer assessment of health care providers and systems. Pain Physician. 2014;17(5):369-377.

15. Cochran WG. Sampling Techniques. 3rd ed. New York, NY: Wiley; 1977.

16. Hinami K, Whelan CT, Wolosin RJ, Miller JA, Wetterneck TB. Worklife and satisfaction of hospitalists: toward flourishing careers. J Gen Intern Med. 2012;27(1):28-36.

17. Patton MQ. Qualitative Evaluation and Research Methods. Thousand Oaks, CA: Sage; 1990.

18. Fishbain DA, Cole B, Lewis J, Rosomoff HL, Rosomoff RS. What percentage of chronic nonmalignant pain patients exposed to chronic opioid analgesic therapy develop abuse/addiction and/or aberrant drug-related behaviors? A structured evidence-based review. Pain Med. 2008;9(4):444-459.

19. Manchikanti L, Cash KA, Damron KS, Manchukonda R, Pampati V, McManus CD. Controlled substance abuse and illicit drug use in chronic pain patients: an evaluation of multiple variables. Pain Physician. 2006;9(3):215-225.

20. Ives TJ, Chelminski PR, Hammett-Stabler CA, et al. Predictors of opioid misuse in patients with chronic pain: a prospective cohort study. BMC Health Serv Res. 2006;6:46.

21. Edlund MJ, Sullivan M, Steffick D, Harris KM, Wells KB. Do users of regularly prescribed opioids have higher rates of substance use problems than nonusers? Pain Med. 2007;8(8):647-656.

22. Silverberg MJ, Ray GT, Saunders K, et al. Prescription long-term opioid use in HIV-infected patients. Clin J Pain. 2012;28(1):39-46.

23. Green CR, Anderson KO, Baker TA, et al. The unequal burden of pain: confronting racial and ethnic disparities in pain. Pain Med. 2003;4(3):277-294.

24. Green CR, Wheeler JR, Marchant B, LaPorte F, Guerrero E. Analysis of the physician variable in pain management. Pain Med. 2001;2(4): 317-327.

25. Hutchinson K, Moreland AM, de CWAC, Weinman J, Horne R. Exploring beliefs and practice of opioid prescribing for persistent noncancer pain by general practitioners. Eur J Pain. 2007;11(1):93-98.

26. Jamison RN, Sheehan KA, Scanlan E, Matthews M, Ross EL. Beliefs and attitudes about opioid prescribing and chronic pain management: survey of primary care providers. J Opioid Manag. 2014;10(6):375382.

27. Nwokeji ED, Rascati KL, Brown CM, Eisenberg A. Influences of attitudes on family physicians' willingness to prescribe long-acting opioid analgesics for patients with chronic nonmalignant pain. Clin Ther. 2007;29(suppl):2589-2602.

28. Miller NS. Failure of enforcement controlled substance laws in health policy for prescribing opiate medications: a painful assessment of morbidity and mortality. Am J Ther. 2006;13(6):527-533.

29. Hoffmann DE, Tarzian AJ. Achieving the right balance in oversight of physician opioid prescribing for pain: the role of state medical boards. J Law Med Ethics. 2003;31(1):21-40.

30. Fishman SM, Papazian JS, Gonzalez S, Riches PS, Gilson A. Regulating opioid prescribing through prescription monitoring programs: balancing drug diversion and treatment of pain. Pain Med. 2004;5(3): 309-324. 
31. Miller J. The other side of trust in health care: prescribing drugs with the potential for abuse. Bioethics. 2007;21(1):51-60.

32. US Drug Enforcement Administration, Department of Justice. Schedules of controlled substances: rescheduling of hydrocodone combination products from schedule III to schedule II. Fed Regist. 2014; 79(163):49661-49682.

33. Fereday J, Muir-Cochrane E. Demonstrating rigor using thematic analysis: a hybrid approach of inductive and deductive coding and theme development. Int J Qual Methods. 2008;5(1):80-92.

34. Bernard HR, Ryan GW. Analyzing Qualitative Data: Systematic Approaches. Thousand Oaks, CA: Sage; 2009.

35. Patton MQ. Qualitative Research and Evaluation Methods, Third Edition. Thousand Oaks, CA: Sage; 2002.

36. Moulin DE, Clark AJ, Gilron I, et al. Pharmacological management of chronic neuropathic pain-consensus statement and guidelines from the Canadian Pain Society. Pain Res Manag. 2007;12(1):13-21.

37. Chou R, Fanciullo GJ, Fine PG, et al. Clinical guidelines for the use of chronic opioid therapy in chronic noncancer pain. J Pain. 2009;10(2): 113-130.

38. Rao JK, Anderson LA, Inui TS, Frankel RM. Communication interventions make a difference in conversations between physicians and patients: a systematic review of the evidence. Med Care. 2007;45(4): 340-349.

39. Kripalani S, Jackson AT, Schnipper JL, Coleman EA. Promoting effective transitions of care at hospital discharge: a review of key issues for hospitalists. J Hosp Med. 2007;2(5):314-323.

40. Sheu L, Fung K, Mourad M, Ranji S, Wu E. We need to talk: primary care provider communication at discharge in the era of a shared electronic medical record. J Hosp Med. 2015;10(5):307-310.

41. Ito TA, Larsen JT, Smith NK, Cacioppo JT. Negative information weighs more heavily on the brain: the negativity bias in evaluative categorizations. J Pers Soc Psychol. 1998;75(4):887-900.
42. Carretie L, Mercado F, Tapia M, Hinojosa JA. Emotion, attention, and the 'negativity bias', studied through event-related potentials. Int J Psychophysiol. 2001;41(1):75-85.

43. Harmon-Jones E, Mills J. Cognitive Dissonance: Progress on a Pivotal Theory in Social Psychology. Washington, DC: American Psychological Association; 1999.

44. Ahmad FS, Metlay JP, Barg FK, Henderson RR, Werner RM. Identifying hospital organizational strategies to reduce readmissions. Am J Med Qual. 2013;28(4):278-285.

45. Edwards PK, Levine M, Cullinan K, Newbern G, Barnes CL. Avoiding readmissions-support systems required after discharge to continue rapid recovery? J Arthroplasty. 2015;30(4):527-530.

46. Elliott DJ, Young RS, Brice J, Aguiar R, Kolm P. Effect of hospitalist workload on the quality and efficiency of care. JAMA Intern Med. 2014;174(5):786-793.

47. Moriates C, Shah NT, Arora VM. A framework for the frontline: how hospitalists can improve healthcare value. J Hosp Med. 2016;11(4): 297-302.

48. Chen LM, Birkmeyer JD, Saint S, Jha AK. Hospitalist staffing and patient satisfaction in the national Medicare population. J Hosp Med. 2013;8(3):126-131.

49. O'Leary KJ, Cyrus RM. Improving patient satisfaction: timely feedback to specific physicians is essential for success. J Hosp Med. 2015; 10(8):555-556.

50. Giacomini MK, Cook DJ. Users' guides to the medical literature: XXIII. Qualitative research in health care B. What are the results and how do they help me care for my patients? Evidence-Based Medicine Working Group. JAMA. 2000;284(4):478-482.

51. Giacomini MK, Cook DJ. Users' guides to the medical literature: XXIII. Qualitative research in health care A. Are the results of the study valid? Evidence-Based Medicine Working Group. JAMA. 2000; 284(3):357-362. 